\title{
QUEEN'S
UNIVERSITY
BELFAST
}

\section{Association between number of siblings and cause-specific mortality in the Glasgow alumni cohort study}

Galobardes, B., McCarron, P., Jeffreys, M., \& Davey Smith, G. (2008). Association between number of siblings and cause-specific mortality in the Glasgow alumni cohort study. European Journal of Epidemiology, 23(2), 8993. https://doi.org/10.1007/s10654-007-9210-6

Published in:

European Journal of Epidemiology

Queen's University Belfast - Research Portal:

Link to publication record in Queen's University Belfast Research Portal

\section{General rights}

Copyright for the publications made accessible via the Queen's University Belfast Research Portal is retained by the author(s) and / or other copyright owners and it is a condition of accessing these publications that users recognise and abide by the legal requirements associated with these rights.

Take down policy

The Research Portal is Queen's institutional repository that provides access to Queen's research output. Every effort has been made to ensure that content in the Research Portal does not infringe any person's rights, or applicable UK laws. If you discover content in the Research Portal that you believe breaches copyright or violates any law, please contact openaccess@qub.ac.uk. 


\title{
Association between number of siblings and cause-specific mortality in the Glasgow alumni cohort study
}

\author{
B. Galobardes · P. McCarron · M. Jeffreys • \\ G. Davey Smith
}

Received: 4 January 2007/Accepted: 7 November 2007/Published online: 21 November 2007

(C) Springer Science+Business Media B.V. 2007

\begin{abstract}
In the Glasgow University Alumni cohort, students with no siblings experienced higher respiratory disease mortality. This risk diminished after accounting for potential confounders. We did not find strong evidence of an association with all cause, coronary heart disease, stroke or stomach cancer mortality. Number of siblings is a proxy for other exposures and exploring its association with specific disease outcomes can help disentangle some of the pathways relating early life exposures to adult mortality.
\end{abstract}

Keywords Siblings Childhood ·

Cause-specific mortality $\cdot$ Life course $\cdot$ Early life exposures

\section{Introduction}

Number of siblings has been related to different health outcomes or disease risk factors in adult life [1-5]. In a Swedish study, having four or more siblings was positively related to poorer health in adulthood, and although there were no differences in mortality risk, only 3 years of mortality follow-up were available [6]. A study in Scotland, with longer follow-up, found that number of

B. Galobardes $(\bowtie) \cdot$ G. Davey Smith

Department of Social Medicine, University of Bristol, Canynge Hall, Whiteladies Rd, Bristol BS8 2PR, UK

e-mail: bruna.galobardes@bristol.ac.uk

\section{P. McCarron}

Department of Epidemiology and Public Health, N. Ireland Cancer Registry, The Queen's University of Belfast, Belfast, UK

M. Jeffreys

Centre for Public Health Research, Massey University,

Wellington, New Zealand siblings was positively related to adult mortality risk for some specific causes of death [7]. Although potentially pointing to exposures and mechanisms linking early life factors and adult health this association has not been systematically investigated in epidemiological studies. For example, more siblings might correlate with more infections during childhood, an exposure which has been positively associated with higher stomach cancer mortality [7] and lower risk of allergy-related diseases [8]. However, greater number of siblings is strongly correlated, in most contemporary industrialized societies, with poor socioeconomic circumstances, which are associated with higher mortality for some causes of death, such as stomach cancer and haemorrhagic stroke and, less strongly, coronary heart disease $[9,10]$. The objective of this study is to investigate the association between number of siblings and causespecific mortality in the Glasgow Alumni Cohort study, a cohort of former students who attended Glasgow University between 1948 and 1968, and on whom we have extensive mortality follow-up.

Detailed information on the Glasgow Alumni Cohort is available elsewhere [11]. Briefly, between 1948 and 1968, students in Glasgow University were invited to attend a health examination carried out by physicians. Information on sociodemographic characteristics, health behaviours and a medical history, were obtained through questionnaire and the physical examination included measurements of height, weight and blood pressure. A total of 11,757 men, representing about $50 \%$ of the complete male student population, participated in the study. Since 1998, approximately $85 \%(n=9,933)$ of the male cohort has been successfully traced through the National Health Service Central Register, which provides continuous updates on the date and cause of death for members of the cohort. Only men are included in this report because of the small number 
of women attending university from 1948 to 1968 and the low number of deaths among women. Participants aged more than 30 years at the time of examination $(n=382)$, one with unknown date of censoring and 4 with missing information on the number of siblings, were excluded resulting in a total of 9,540 men. For multivariable analysis, we further excluded those with missing information on confounding variables $(n=879)$ resulting in 8,661 men, 1,439 deaths and 387 censored observations (participants who have given official notification of residing overseas).

Childhood socioeconomic position was assigned by coding father's occupation into a five-point scale from I (most affluent) to V (least affluent), using the Registrar General's classification, which, in this cohort, is associated with cardiovascular disease mortality [12]. Age (years), number of siblings, height (m), body mass index (BMI) $\left(\mathrm{kg} / \mathrm{m}^{2}\right)$, systolic and diastolic blood pressure $(\mathrm{mmHg})$, current smoking habit and occasional or regular alcohol consumption were recorded while at university. Two students with missing date of birth were assigned the median age of the students who attended the survey on the same year.

ICD9 and ICD10 codes were used to group the underlying cause of death into the following groups: CVD (ICD9: 390-459; ICD10:I00-I99, G45); CHD (ICD9: 410414, 429.2; ICD10: I20-I25, I51.6); stroke (ICD9: 430438; ICD10: I60-I69, G45); all cancers (ICD9: 140-208; ICD10: C00-C97); lung cancer (ICD9: 162; ICD10: C34); stomach cancer (ICD9: 231; ICD10: C16); prostate cancer (ICD9: 185; ICD10: C61); respiratory disease (ICD9: 460519; ICD10: J00-J99); and, external causes of death, including accidents, suicide and violence (ICD9: 800-999, E800-E999; ICD10: S00-T98, V01-Y89).

Cox proportional hazards models, with age as the time scale variable (therefore age-adjusted), were used to estimate the hazard ratio of overall and cause-specific mortality associated with number of siblings, adjusting for examination date, socioeconomic position and disease risk factors measured at university. The assumption of proportional hazards across exposure groups was graphically investigated with $\log -\log$ plots and formally tested with the Schoenlfeld test. If the assumption was violated due to one of the confounder variables, the analysis were carried out stratifying for this variable (e.g. for CVD, CHD with smoking while at university). Continuous variables were centred to their mean value. The 1-sibling category of the explanatory variable was used as the reference level because of the higher number of observations in this category.

The distribution of number of siblings was skewed with median 1 sibling, interquartile range (IQR) from 1 to 2 siblings and overall range extending from 0 to 13 siblings. The median and spread of number of siblings was similar among students with fathers in social classes I-III (median $=1, I Q R=1,2$ ) whereas those with fathers in classes IV and $\mathrm{V}$ belonged to families with a greater median number of siblings (median $=2, \mathrm{IQR}=1,3$ among class IV and $\mathrm{IQR}=1,4$ among class V).

Older students tended to have more siblings (linear trend $P<0.001$ ) (Table 1). Height, systolic and diastolic blood pressure and history of hay fever were inversely related to number of siblings (linear trend $P \leq 0.001$ ) whereas BMI was similar across all groups (linear trend $P=0.11$ ). Smoking and lower parental social class were more prevalent among students with a higher number of siblings but there were no differences in alcohol consumption or history of asthma. History of bronchitis was lowest among those with two or three siblings and there was evidence of a quadratic trend $(P=0.003)$.

There was weak evidence that men with higher number of siblings had greater all-cause (adjusted hazard ratio (HR) for a linear trend across sibling categories $=1.02$; 95\% confidence interval $(\mathrm{CI})=0.98,1.06$ ), CVD (adjusted HR for linear trend $=1.04$; 95\%CI: 0.97 1.11) and CHD (adjusted HR linear trend $=1.02$ 95\%CI: 0.95-1.11) mortality (Table 2). Stroke, all cancer, lung and stomach cancer mortality were not associated with number of siblings. There was a $17 \%$ increase in the hazard of dying of prostate cancer for each additional sibling (95\%CI: 0.951.44). Respiratory disease mortality was highest among those with no siblings (adjusted HR $=1.69,95 \%$ CI: 0.97, 2.94) and among those with four or more siblings (adjusted $\mathrm{HR}=1.43,95 \% \mathrm{CI}: 0.74,2.75)$. There was evidence against a simple linear trend for the hazard of respiratory disease mortality $(P$-value for the quadratic term $=0.02)$. There was no association with external causes of death.

In our study, there was weak evidence that mortality risk varied according to number of siblings. Furthermore, this weak increase in risk was not confirmed for CHD or stroke mortality. Hart et al. reported a higher risk of haemorrhagic stroke with greater number of siblings [7] but in the current study there were insufficient confirmed deaths from haemorrhagic and ischemic stroke to assess these outcomes separately. We did not find a previously reported higher mortality due to stomach cancer [7], which is thought to indicate a higher risk of infection by Helicobacter Pylori in childhood. Increasing sibling number can lead to a higher transmission rate of an infectious agent, but this may actually occur only in the presence of other risk factors, such as overcrowding. In the Glasgow cohort, generally a more homogeneously advantaged subgroup compared to the general population, although higher number of siblings was more common among families of lower socioeconomic background, there were also large families among higher socioeconomic groups among whom overcrowding is unlikely to have occurred. 


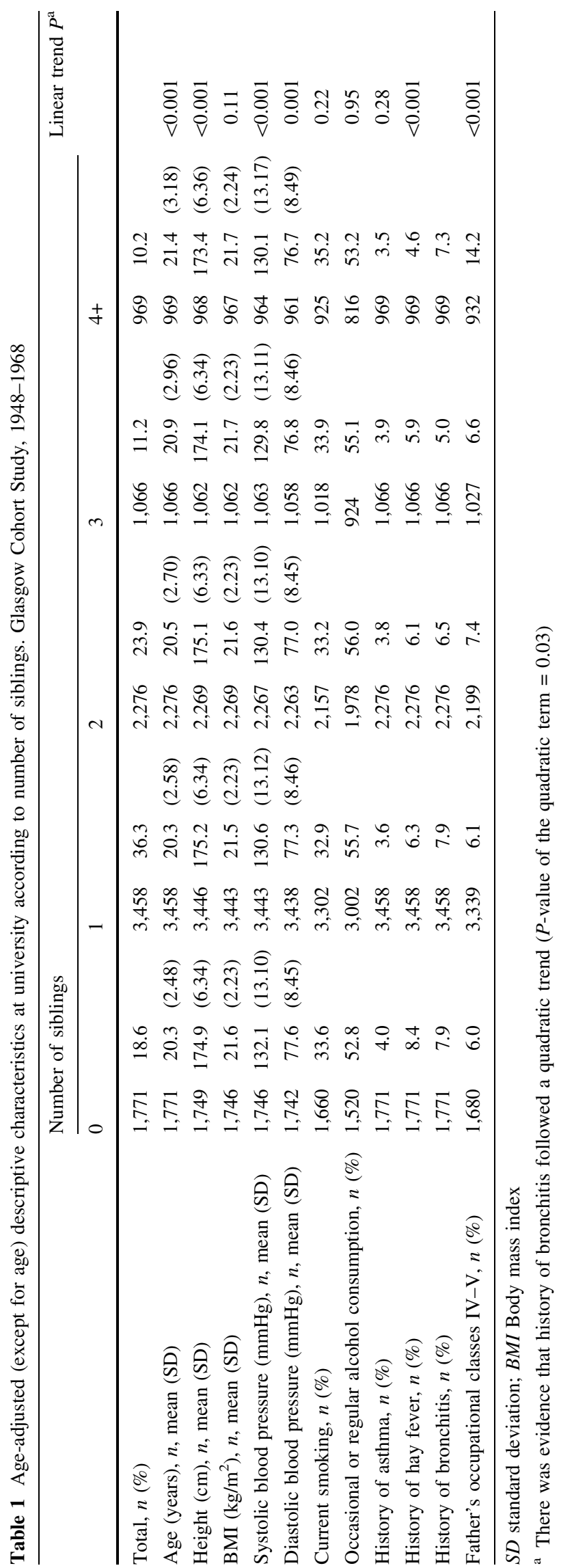

Mortality risk due to respiratory diseases was highest among those with no siblings followed by those with four or more siblings, although these did not reach conventional levels of statistical significance. The increased risk among those with no siblings was attenuated, although remained present, after adjustment of disease risk factors. These results suggest that number of siblings is a proxy for early life exposures, other than smoking, that result in higher adult mortality. We previously reported an association between number of siblings and history of allergic diseases in this cohort [13]. It is unlikely that this pattern of risk is due to residual confounding of unmeasured smoking given that there was no association between number of siblings and lung cancer mortality, an outcome with a much stronger association with smoking. In addition, this population has experienced relatively homogenous favourable socioeconomic conditions in adulthood, thus reducing the impact of this important confounder in the study design.

Finally, we found some evidence of a higher risk of prostate cancer mortality with increasing number of children. Adjustment for the available variables increased, rather than diminished, the association. Although total number of siblings was not related to prostate cancer incidence, men who had five or more older siblings had a $38 \%$ higher risk of prostate cancer in a recent Swedish study [14]. The authors suggested that surveillance bias, where men with older siblings, particularly if affected by prostate cancer, would be more likely to follow medical examinations or participate in screening programs [14]. It would be interesting to see if these results can be replicated in other cohorts.

Number of siblings per se is not the exposure variable that confers an increased mortality risk. Number of siblings has been traditionally used as a proxy for two exposures, poor early life socioeconomic circumstances (in industrialized societies) and exposure to early life infections (e.g. for stomach cancer [7] and allergic diseases [13]). These are the main pathways that are hypothesized in this manuscript. This may still be the case in younger cohorts but additional pathways could also be relevant for specific outcomes. For example, it was recently proposed that increased prostate cancer risk associated with increasing number of siblings could reflect greater medical surveillance among younger siblings of men previously diagnosed with this disease [14].

The results presented here are based on a large cohort with a substantial follow-up. While there was enough power to investigate the most common causes of death in this population, it was limited for some specific causes of mortality, in particular, some cancers.

In summary, our study did not find strong evidence to support the hypothesis that CHD, stroke and stomach cancer mortality are associated with number of siblings. 
Table 2 Adjusted hazard ratio and 95\% confidence interval (CI) for cause-specific mortality associated with number of siblings in men (Glasgow Cohort Study, 1948-1968)

\begin{tabular}{|c|c|c|c|c|c|c|c|c|c|c|c|c|c|c|c|c|}
\hline \multirow[t]{3}{*}{ Cause of death (number of deaths) } & \multicolumn{13}{|c|}{ Number of siblings } & \multicolumn{3}{|c|}{$\overline{\text { Linear increase in } \mathrm{HR}^{\mathrm{c}}}$} \\
\hline & \multicolumn{3}{|l|}{0} & \multirow[t]{2}{*}{1 (ref.) } & \multicolumn{3}{|l|}{2} & \multicolumn{3}{|l|}{3} & \multicolumn{3}{|l|}{$4+$} & \multirow[b]{2}{*}{ HR } & \multirow[b]{2}{*}{$95 \%$} & \multirow[b]{2}{*}{$\mathrm{CI}$} \\
\hline & HR & $95 \%$ & CI & & HR & $95 \%$ & $\mathrm{CI}$ & HR & $95 \%$ & CI & HR & $95 \%$ & CI & & & \\
\hline All causes ${ }^{\mathrm{a}}(n=1,439)$ & 1.00 & 0.86 & 1.17 & 1.0 & 1.06 & 0.92 & 1.21 & 1.05 & 0.88 & 1.25 & 1.12 & 0.94 & 1.33 & 1.03 & 0.99 & 1.07 \\
\hline Fully adjusted ${ }^{\mathrm{b}}$ & 0.99 & 0.85 & 1.15 & 1.0 & 1.05 & 0.91 & 1.20 & 1.02 & 0.86 & 1.22 & 1.07 & 0.90 & 1.27 & 1.02 & 0.98 & 1.06 \\
\hline $\left.\operatorname{CVD}^{\mathrm{a}} n=558\right)$ & 0.88 & 0.68 & 1.13 & 1.0 & 1.13 & 0.91 & 1.40 & 0.89 & 0.66 & 1.19 & 1.21 & 0.93 & 1.57 & 1.06 & 0.99 & 1.13 \\
\hline Fully adjusted ${ }^{\mathrm{b}}$ & 0.85 & 0.66 & 1.10 & 1.0 & 1.11 & 0.89 & 1.38 & 0.85 & 0.63 & 1.14 & 1.12 & 0.86 & 1.46 & 1.04 & 0.97 & 1.11 \\
\hline $\left.\mathrm{CHD}^{\mathrm{a}} n=377\right)$ & 0.91 & 0.67 & 1.23 & 1.0 & 1.11 & 0.85 & 1.44 & 0.96 & 0.68 & 1.37 & 1.13 & 0.82 & 1.57 & 1.04 & 0.96 & 1.13 \\
\hline Fully adjusted $^{\mathrm{b}}$ & 0.87 & 0.64 & 1.19 & 1.0 & 1.08 & 0.83 & 1.41 & 0.92 & 0.65 & 1.30 & 1.02 & 0.73 & 1.43 & 1.02 & 0.95 & 1.11 \\
\hline Stroke $^{\mathrm{a}}(n=115)$ & 0.71 & 0.38 & 1.35 & 1.0 & 1.02 & 0.62 & 1.70 & 0.77 & 0.38 & 1.55 & 1.13 & 0.62 & 2.06 & 1.06 & 0.91 & 1.24 \\
\hline Fully adjusted ${ }^{\mathrm{b}}$ & 0.71 & 0.38 & 1.33 & 1.0 & 1.01 & 0.61 & 1.69 & 0.73 & 0.36 & 1.48 & 1.05 & 0.57 & 1.92 & 1.04 & 0.89 & 1.22 \\
\hline All cancer ${ }^{\mathrm{a}}(n=507)$ & 1.06 & 0.82 & 1.36 & 1.0 & 1.09 & 0.86 & 1.37 & 1.06 & 0.79 & 1.42 & 1.02 & 0.76 & 1.37 & 1.00 & 0.93 & 1.08 \\
\hline Fully adjusted $^{\mathrm{b}}$ & 1.06 & 0.83 & 1.37 & 1.0 & 1.08 & 0.86 & 1.36 & 1.05 & 0.79 & 1.41 & 1.01 & 0.75 & 1.37 & 1.00 & 0.93 & 1.07 \\
\hline Lung cancer ${ }^{\mathrm{a}}(n=95)$ & 1.03 & 0.57 & 1.85 & 1.0 & 1.06 & 0.62 & 1.81 & 1.25 & 0.67 & 2.34 & 0.71 & 0.33 & 1.54 & 0.97 & 0.82 & 1.14 \\
\hline Fully adjusted $^{\mathrm{b}}$ & 1.01 & 0.56 & 1.81 & 1.0 & 1.05 & 0.61 & 1.79 & 1.19 & 0.63 & 2.23 & 0.64 & 0.29 & 1.39 & 0.95 & 0.81 & 1.12 \\
\hline 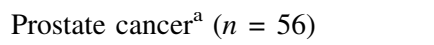 & 0.66 & 0.26 & 1.67 & 1.0 & 1.34 & 0.68 & 2.63 & 1.30 & 0.56 & 2.98 & 1.26 & 0.55 & 2.90 & 1.15 & 0.94 & 1.41 \\
\hline Fully adjusted $^{\mathrm{b}}$ & 0.68 & 0.27 & 1.73 & 1.0 & 1.39 & 0.71 & 2.73 & 1.37 & 0.59 & 3.17 & 1.35 & 0.58 & 3.15 & 1.17 & 0.95 & 1.44 \\
\hline Stomach cancer ${ }^{\mathrm{a}}(n=18)$ & 1.00 & 0.25 & 4.00 & 1.0 & 1.00 & 0.28 & 3.54 & 1.47 & 0.37 & 5.87 & 0.98 & 0.20 & 4.87 & 1.04 & 0.72 & 1.51 \\
\hline Fully adjusted $^{\mathrm{b}}$ & 1.00 & 0.25 & 4.01 & 1.0 & 1.00 & 0.28 & 3.56 & 1.35 & 0.33 & 5.43 & 0.83 & 0.16 & 4.16 & 1.00 & 0.69 & 1.45 \\
\hline Respiratory disease $^{\mathrm{a}}(n=91)$ & 1.81 & 1.05 & 3.14 & 1.0 & 0.84 & 0.45 & 1.58 & 1.16 & 0.57 & 2.34 & 1.49 & 0.78 & 2.84 & & & \\
\hline Fully adjusted $^{\mathrm{d}}$ & 1.69 & 0.97 & 2.94 & 1.0 & 0.84 & 0.45 & 1.59 & 1.15 & 0.57 & 2.33 & 1.43 & 0.74 & 2.75 & & & \\
\hline External causes ${ }^{\mathrm{a}}(n=79)$ & 1.27 & 0.72 & 2.26 & 1.0 & 0.56 & 0.28 & 1.11 & 1.15 & 0.58 & 2.30 & 0.90 & 0.41 & 1.96 & 0.91 & 0.76 & 1.10 \\
\hline Fully adjusted $^{\mathrm{b}}$ & 1.29 & 0.73 & 2.30 & 1.0 & 0.56 & 0.28 & 1.12 & 1.20 & 0.60 & 2.40 & 0.95 & 0.43 & 2.10 & 0.92 & 0.76 & 1.11 \\
\hline
\end{tabular}

CVD cardiovascular disease; $C H D$ coronary heart disease

a Adjusted for date of examination

b Adjusted for date of examination, father's social class, height, body mass index, systolic blood pressure and smoking at university

c There was evidence that the HR of respiratory disease followed a quadratic trend

d Adjusted for date of examination, father's social class, height, body mass index, systolic blood pressure, smoking at university, history of asthma, hay fever and bronchitis at university

However, we did find a higher risk of respiratory disease mortality among those with no siblings that cannot be fully accounted for by exposure to tobacco smoking, which diminished after adjusting for early life exposure to respiratory diseases. Thus, number of siblings is a useful variable that seems to act as a proxy of different pathways specific to different outcomes. Information from historical cohorts can help disentangle these mechanisms.

Acknowledgments The authors would like to acknowledge the financial support of the Stroke Association; Chest, Heart and Stroke Scotland; the National Health Service Research and Development Cardiovascular Disease Programme; and the World Cancer Research Fund. B. G. is funded by the Medical Research Council through Research Fellowship in Health of the Public. P. M. is supported by a career scientist award funded by the Research and Development Office for Health and Personal Social Services in Northern Ireland. The Centre for Public Health Research (Massey University, Wellington, New Zealand) is supported by a Programme Grant from the Health Research Council of New Zealand. The authors' work was independent of the funding sources

\section{References}

1. Moyes CD. Stature and birth rank. A study of schoolchildren in St Helena. Arch Dis Child 1981;56:116-20.

2. O'Leary SR, et al. Is birth order associated with adult mortality? Ann Epidemiology 1996;6:34-40.

3. Wagner ME, et al. Family size effects: a review. J Genet Psychol 1985;146:65-78.

4. Whincup P, et al. Relation of blood pressure to number of siblings. N Engl J Med 1991;325:891.

5. Okasha M, et al. Determinants of adolescent blood pressure: findings from the Glasgow University student cohort. J Hum Hypertens 2000;14:117-24.

6. Lundberg $\mathrm{O}$. The impact of childhood living conditions on illness and mortality in adulthood. Social Sci Med 1993;36:1047-52.

7. Hart CL, Davey Smith G. Relation between number of siblings and adult mortality and stroke risk: 25 year follow up of men in the Collaborative study. J Epidemiol Community Health 2003;57:385-91.

8. Ball TM, et al. Siblings, day-care attendance, and the risk of asthma and wheezing during childhood. $\mathrm{N}$ Engl $\mathrm{J}$ Med 2000;343:538-43. 
9. Galobardes B, et al. Childhood Socioeconomic Circumstances and Cause-specific Mortality in Adulthood: Systematic Review and Interpretation. Epidemiol Rev 2004;26:7-21.

10. Davey Smith G, et al. Adverse socioeconomic conditions in childhood and cause specific adult mortality: prospective observational study. BMJ 1998;316:1631-35.

11. McCarron P, et al. Life course exposure and later disease: a follow-up study based on medical examinations carried out in Glasgow University (1948-68). Public Health 1999;113:265-71.
12. Galobardes B, et al. Childhood socioeconomic circumstances predict specific causes of death in adulthood: the Glasgow student cohort study. J Epidemiol Community Health 2006;60:527-29.

13. Kinra S, et al. Association between sibship size and allergic diseases in the Glasgow Alumni Study. Thorax 2006;61:48-53.

14. Altieri A, Hemminki K. Number of siblings and the risk of solid tumours: a nation-wide study. Br J Cancer 2007;96:1755-59. 